\title{
0 Instituto da Universidade de Moscou e os estudos soviéticos de jornalismo dos anos 1920: projeto científico inacabado
}

Francisco Rüdiger

\section{Resumo}

Ainda é pouco conhecido no Ocidente 0 fato de, na União Soviética dos anos 1920, ter sido esboçado, no Instituto de Jornalismo da Universidade de Moscou, um programa de pesquisa e um sistema teórico para a reflexão e análise da imprensa em uma sociedade comunista. 0 artigo apresenta as circunstâncias, os sujeitos, as principais ideias e as linhas de estudo que definiram este fenômeno, coincidente com os anos em que o país viveu a "nova política econômica". 0 argumento revela que, no período, os estudiosos soviéticos se esforçaram por elaborar uma teoria marxista da informação de classe como forma de manter uma relativa autonomia do jornalismo em relação à doutrina leninista da propaganda e organização professada oficialmente pelo regime.

\section{Palavras-Chave}

Teorias do jornalismo. Marxismo. Escola soviética.
Francisco Rüdiger | frudiger@ig.com.br Doutor em Ciências Sociais pela Universidade de São Paulo, professor do Programa de Pós-Graduação da Pontifícia Universidade Católica - PUCRS e da Universidade Federal do Rio Grande do Sul UFRGS, Brasil.
Apesar do decreto que, desde 1865, estabelecia censura prévia e punições severas a seus crimes, a imprensa russa viveu no final do século XIX período de expansão, associado à formação de distintos públicos nas grandes cidades do Império. Havia um movimento de relativa modernização no setor econômico, que repercutiu na dinâmica societária e vida intelectual do país. Por um lado, apareceu um jornalismo literário de espírito cosmopolita, em cujas páginas, de grande formato, reverberavam discussões por vezes eruditas sobre questões de cultura, política e sociedade. De outro, surgiu um jornalismo de boulevard, como se tornou comum chamar por lá, cujo forte eram as notícias ligeiras, publicadas em folhas de formato pequeno e preço módico, destinadas às camadas populares com poder de compra: funcionários de baixo escalão, varejistas, empregados, etc. (McReynolds, 1991).

Após a Revolução de 1905 e 0 fim da legislação repressiva, o processo se acentuou, introduzindo distinção que viraria clássica no meio intelectual entre publicística (публитсистика, publitsistika), o emprego de impressos, entre 
outros meios, com o objetivo de, periodicamente ou não, articular opiniões e influenciar o público; e jornalismo (зурналистика, zurnalistika), 0 emprego dos periódicos em papel, mais tarde outros meios, com a finalidade de, além disso, veicular notícias e informações (Byford, 2007, p. 1/66; Juskevits, 2002, p. 37; Pasti, 2005; Tolstikova, Keiyton, 2002). A esfera pública que se esboçara no período anterior assumiu contornos melhor definidos, ainda que muito restritos socialmente, em cujo âmbito despontava um estamento intelectual especialmente forte $\mathrm{e}$ influente e do qual fazia parte, enquanto segunda classe, o pessoal de redação e reportagem dos jornais (McReynolds, 1991, p. 161).

\begin{abstract}
No final do século XIX, os jornais se tornaram empresas comerciais lucrativas. Houve um aumento no número de tablóides, desenhados para agradar 0 gosto filisteu urbano, como o Peterburgskii listok [Folha de São Petersburgo] (1864-1917), 0 Moskovskii listok [Folha de Moscou] (1881-1918) e, mais tarde, o reacionário Gazeta-kopeika [Gazeta de Preço Módico] (1908-18), cuja circulação era de 300.000 . Na mesma época, surgiram novos jornais burgueses, entre os quais o Russkoe slovo [Palavra Russa] (1895-1917). Em 1900, era publicado um total de 125 jornais, e os que tinham maior circulação tiravam, em média, 100 mil exemplares diários (Prokhorov, 1973-1979; cf. Hamburg, 2010, p. 59-60).
\end{abstract}

Ainda assim, havia apenas dois periódicos por cada cem habitantes em 1913. 0 avanço no debate público sobre os temas de interesse nacional e atualidade se manteve restrito. 0s envolvidos se restringiam aos setores urbanos e intelectualizados. A massa da população era analfabeta e permanecia alheia da vida pública.
Por outro lado, o crescimento do pessoal empregado no setor e 0 aumento do interesse no assunto fizeram surgir preocupações de ordem profissional e intelectual entre a categoria. A classe jornalística se organizava e, com tanto, passou ela mesma a responder às demandas por formação. Em 1912, surge a revista Oficina de Imprensa, em cujas páginas aparecem, sobretudo, matérias de interesse profissional, mas também os primeiros debates sobre a situação e rumos do jornalismo na Rússia (cf. Zhikov, 2011).

As revoluções de 1917 tiveram profundo impacto em todo este cenário, abrindo época que se estenderia até 0 final do século XX. A primeira, em fevereiro, decidiu pela volta da censura e pelo fechamento de periódicos, a despeito do cunho burguês e liberal. A segunda, em outubro, não apenas acentuou estas medidas, mas, de acordo com seu cunho proletário e socialista, determinou a nacionalização da imprensa. 0s bolchevistas, certo, incentivaram o desenvolvimento da imprensa, que cresceu em veículos, tiragens e leitores, até pelo incentivo que deram à escolarização, mas, por outro lado, submeteram toda a atividade editorial à doutrina leninista da agitação, propaganda e organização, convertida em política de Estado após eles assumirem 0 comando do país. 0 jornalismo, aos poucos, entrou em eclipse, do qual só começaria a sair após 1991, com o fim da União Soviética.

0 texto que segue apresenta a primeira notícia, em língua portuguesa, do esforço no sentido de 
matizar este processo e desenvolver uma teoria marxista da informação jornalística naquele país durante a década de 1920.

\section{Os Congressos de Jornalistas e as origens do Instituto da Universidade de Moscou}

Dentre os inúmeros desafios enfrentados no período conhecido como "comunismo de guerra" (1917-1921), a liderança soviética se deparou com a necessidade de assegurar e desenvolver os meios materiais e redes de informação herdados do regime imperial. Diante da insurgência contrarrevolucionária, o confronto com exércitos estrangeiros e a pequena base de massas do partido, fazia-se mister contar com este recurso para afirmar o poderio soviético. Questão de urgência, neste contexto, consistia a falta de pessoal especializado. A vanguarda partidária era formada, em sua maior parte, por intelectuais experimentados nas lides publicísticas, mas as tarefas eram muitas e faltava gente. 0 s homens de letras, escritores e jornalistas, haviam em grande parte aderido à oposição ou deixado o país também.

A agência Rosta, criada em 1918 (Kruglak, 1962, p. 19-26), solucionou como pôde muitos destes problemas, inclusive 0 treinamento de pessoal para trabalhar na imprensa e serviços de comunicação, mas passado o período mais duro e desesperador, chegou-se à conclusão que era preciso providenciar preparo mais profundo e especializado para quem desejava militar na imprensa. Os cursos de pequena duração que ela havia criado na capital e em outras cidades não eram suficientes para formar os profissionais com que a liderança soviética desejava contar para operar os meios de agitação e propaganda e, assim, ajudar a engajar o cidadão soviético na construção do socialismo.

Durante os Congressos de Jornalistas que se reuniram em Moscou em 1918/1919, foi decidido que, no novo regime, não haveria imprensa independente: os jornalistas serviriam à causa soviética (Tucker, 1985, p. 147). Os serviços jornalísticos propagandeariam as políticas do partido, trabalhando para mobilizar a população em seu favor, em vez de fornecer informação e notícias de acordo com princípios profissionais autônomos (Kenez, 1985). Instituiu-se uma espécie de vício original, sancionado pelo regime, e que marcou a trajetória do pensamento comunista a respeito da imprensa. Notáveis como Alexandra Kollontai, Kamenev, Krupskaya, Radek, Kerzehnstsev e outros acordaram, em meio à polêmica, que vigoraria 0 oficialismo. Abriu-se espaço para a doutrina da notícia como agitação por meios de fatos que se implantaria por completo nos anos 1930. 0 jornalismo foi definido como uma forma de aplicação dos princípios da propaganda ao relato cotidiano e ligeiro dos fenômenos sociais.

A crítica, ficou claro dali por diante, era categoria aplicável ao jornalismo burguês, que pretende ser livre e estar acima de partidos sem podê-lo: 
não há razão para aquela primeira existir no regime comunista. A função que, neste sentido, a imprensa bolchevista tem de exercer nos países capitalistas se transmuta, no comunismo, na prática da autocrítica socialista, exercida através de discussões travadas dentro do partido, sem direito a acompanhamento pelo público mais amplo.

Por outro lado, foram importantes os debates feitos em torno da estratégia com que a classe jornalística se engajaria no processo revolucionário. 0 controle da imprensa por parte do Estado era talvez menos importante do que a luta para libertá-la dos princípios burgueses, em meio aos quais ela surgira e se desenvolvera. A hora era não apenas de criar um novo jornal, mas formar seu devido tipo de leitor, oriundo da classe operária e das massas camponesas, visando redefinir os rumos da atividade editorial nos vastos territórios do antigo império russo.

Havia por parte dos congressistas plena consciência de que, sem elevar o nível intelectual da população, não seria possível sequer assegurar o triunfo da revolução, como disse Lênin, ao recomendar que os jornais, todavia, também trabalhassem com informações úteis, sobretudo econômicas (Lênin, [1918] 1976, p. 159-160). Também se ouviam forte as vozes que desejavam se valer da imprensa para integrar o povo aos trabalhos do partido, convocando os trabalhadores a participar das tarefas da redação, os leitores a colaborarem com os jornalistas. Almejava-se criar um novo tipo de imprensa, mas em torno desta ideia sempre houve ambiguidade (Korkonosenko, 2001, p. 71-76).

Nesta época, por exemplo, pregou-se que a participação do povo era essencial para reformar a sociedade e levá-la da ditadura do proletariado para o socialismo democrático. A ampliação dos mecanismos de participação da população na vida governamental e órgãos do Estado era considerada questão estratégica, mas não faltava quem defendesse a instrumentalização de cima para baixo, tecnocrática, do aparato publicístico. Madame Krupskaya chegou a defender que 0 Estado deveria ser substituído por organizações públicas, entre as quais incluía a imprensa, mas também achava que a sociedade devia ser vigiada e controlada para não haver recuo na revolução e no que ela havia conquistado (cf. Volkov, 1998).

Em geral, predominava 0 entendimento de que "A missão principal e mais importante que os jornalistas soviéticos tinham era legitimar 0 novo governo soviético e criar a imagem de uma autoridade política capaz de servir de base para obter a lealdade dos cidadãos" (Brooks,1985a, p. 29; cf. Prokhorov, 1973-1979a). A Constituição garantiria aos cidadãos a liberdade de manifestação e 0 acesso a seus meios, desde que em acordo com os interesses do povo e de uma forma consoante ao desenvolvimento do sistema socialista soviético.

Os projetos eram muitos, indo da formação de comitês integrados de trabalhadores para tomada 
de decisões nos estabelecimentos editoriais até a invenção de novas formas de se comunicar com as massas, como foram, em seu tempo, os jornais murais, as vitrines de informação, as encenações de notícias e os vagões de propaganda postos nas composições ferroviárias (cf. Harrison, 1921, p. 60-66; Medvedkin [1934]1973).

As resoluções incluíram com o tempo a decisão, posteriormente adotada e sistematizada pelo partido, de segmentar a atividade editorial e incluir novos leitores. A preocupação em desenvolver as formas de consciência de cada grupo de acordo com as linhas de classe e graus de consciência política do público sempre foi tida como estratégica.

Resumidamente, 0 assunto passava por dois eixos, desde o ponto de vista da formação do pessoal requerido: um, era o estudo e teorização do tipo de público e a espécie de jornal a serem criados e desenvolvidos em uma sociedade comunista; o outro, era a criação de um estabelecimento de ensino e pesquisa capaz de formar o pessoal habilitado a conduzir estas tarefas tanto no periódico quanto na ciência. Atendimento governamental desta expectativa foi a criação, em 1921, do Instituto Estatal de Jornalismo da Universidade de Moscou (cf. Mueller, 1998; Fitzpatrick, 1992, p. 37-64).

Havia planos desde o início do século no sentido de criar um estabelecimento deste tipo no seio do Império Russo. Em 1905, chegara a funcionar por alguns meses um curso na Universidade de São
Petersburgo. A Revolução ocorrida naquele ano 0 abortou. Pioneiro da bibliologia russa, Nikolai Lisowski avançou no assunto. Quando da criação de cátedra para a matéria na mesma Universidade (1913), ele apresentou sua ciência como disciplina teorética, prática e técnica, que incluiria os periódicos como objeto de estudo. Introdutor do termo jornalismo, no sentido de publicismo feito por meio dos periódicos, o erudito havia procedido a uma vasta compilação e indexação de títulos em 1895 (Byford, 2007).

A Associação da imprensa periódica começou a oferecer cursos de pequena duração em 1913 e, na Universidade de Moscou, havia nessa época um seminário dominical muito concorrido, oferecido pelo professor Vladimirov (Jaeger, [1926] 1996, p. 33). A literatura disponível era, contudo, muito pobre, o principal provindo de revistas literárias e publicações especializadas editadas no meio profissional. Diretor da agência Rosta (1919-1920), Platon Kerzhentsov (1881-1940), então diretor da divisão de imprensa do Agitprop, publicou $O$ jornal, organização e técnica (1919), para servir de manual aos estudantes em treinamento nos cursos de pequena duração por ela oferecidos. Apesar de tirar seis edições e receber endosso do partido, o livro tinha pouca ou nenhuma reflexão, concentrando-se em tópicos de cunho técnicoprofissionalizantes, superficialmente encobertos por discurso político-doutrinário.

0 Instituto de Jornalismo criado pelo novo regime tomou para si este tipo de tarefa e 
seguiu produzindo este tipo de literatura, muito importante na preparação profissional para trabalhar na atividade gráfica e editorial. Foram vários os manuais por ele publicados na década de 1920. Konstantin Novitsky (18791960), responsável pelos cursos de curta direção oferecidos na agência Rosta, nomeado seu primeiro diretor, entretanto, tinha mais pretensões para o estabelecimento. Sintonizado com o movimento em curso na Alemanha, ele reclamou para o estudo do jornalismo autonomia como ciência, em 0 jornalismo como tema de investigação (1924).

Em 1926, Vladislav Evgenevich Maksimov (18831953) formaria grupo em Leningrado para estudar a história do jornalismo, cujo trabalho História do jornalismo russo (1930) abriu caminho para sua supremacia, junto com os departamentos interessados no estudo de sua administração, no meio acadêmico da área nos anos 1930.

Adotando um viés histórico ou profissionalizante, quando não biográfico, superficialmente influídos pela teoria marxista da luta de classes, estas especialidades lograram sobreviver à conjuntura adversa, adaptando-se aos preceitos doutrinários stalinistas que vigoraram à época.

Novitsky tinha muito mais em vista. Para ele, o estudo do jornalismo periódico (газетоведениуа, gazetovedeniya), seja em jornais, seja em revistas, inclui todos os conhecimentos relativos aos periódicos e tem por objetivo examinar suas circunstâncias de produção industrial, feitura gráfica e editorial, distribuição material e uso ideológico, quer no presente, quer no passado. Leitor dos escritos de Karl Bücher (cf. Bücher, 1926), ele pregou que o estudo do jornalismo deveria ser histórico e sistemático, qualitativo e quantitativo, fazer levantamento estatístico tanto quanto crítica ideológica do fenômeno.

A União Soviética, observou, estava atrasada em relação a países como os Estados Unidos, Inglaterra, Alemanha e Polônia na prática e no estudo do jornalismo, o que conferia ainda mais legitimidade às atividades do Instituto. Desafio do mesmo era, segundo ele, não apenas ajudar a erguer o novo jornalismo do país, mas colocá-lo à altura dos estudos e do ensino feitos internacionalmente. Para tanto, seria importante, contudo, que se lograsse identificar sua especificidade, se definisse uma abordagem e se estabelecesse um foco temático distinto do de outras disciplinas (cf. Korkonosenko, 2001. p 77-80).

\section{Dos estudos do leitor à teoria do jornalismo}

Durante os primeiros anos da Revolução, houve esperança em parte da liderança soviética de que a imprensa partidária poderia desempenhar uma função politicamente educativa e orientadora para o cidadão. Seguindo o entendimento publicístico burguês, sem endossar suas premissas pluralistas e liberais, o publicismo através dos periódicos foi visto por ela como orientação política e liderança ideológica, razão de ser da própria imprensa. A matéria conservava certa plasticidade, excluindo 
um entendimento puramente instrumental, como dá exemplo manifestação de Madame Krupskaya:

Os jornais são importantes para quem deseja se orientar em relação aos acontecimentos contemporâneos. 0 Pravda e outros Ihe permitem entender muita coisa [...] enquadrar o pensamento em certo sentido, chamar a atenção sobre um fato determinado, enfocar um problema; isto é, fazem que nem um conferencista talentoso e bem informado: impulsionam o pensamento em determinada direção, abrem perspectivas, assinalam os problemas importantes e o modo de enfocá-los (Krupskaya, [1922]1978, p. 63).

Ainda bem cedo também se manifestou, contudo, tendência a ver na imprensa simples correia de transmissão das decisões do partido, mecanismo de organização das massas e arma de emprego ligeiro nas campanhas em que essas deveriam ser engajadas. 0 partido comunista não tinha que falar com e convencer as massas trabalhadoras através dos meios ao seu alcance. 0 partido estava sempre e por definição em contato e interação com elas, era o seu canal de expressão, como defendeu Stalin.

A tarefa imediata da imprensa é fazer com que os jornais se tornem meios de organização coletiva em favor do partido e do regime soviético, meios de estabelecer conexões com a massa da classe trabalhadora em nosso país e integrá-la no partido e no regime. [...] A imprensa, uma das correias de ligação entre 0 partido e as massas [...] deve fazer com que seus fios, saindo do partido, corram através de todos os distritos operários e camponeses sem exceção, de modo que a interação entre o partido e o estado, por um lado, e os distritos industriais e campesinos, de outro, seja sempre completa (Stalin, [1923a] 1954, p. 288).
Por vezes objeto de exaltação ingênua, noutras de repulsa sumária e indignada, o fenômeno dos leitores-correspondentes é uma prova viva da forma como estas perspectivas se entrelaçavam e geravam tensões na prática cotidiana. 0 movimento surgiu de baixo para cima, conforme a atividade editorial e os indicadores de leitura se expandiam em número e variedade (cf. Lovell 2000). Aos poucos, as redações foram sendo invadidas por relatos expressando os problemas, anseios, opiniões e denúncias da população sobre o que ocorria em seu lugar de moradia e trabalho, muito mais que a respeito das grandes questões do país.

Entre 1921 e 1922, houve o início de um movimento de massas nesse sentido, que, rápido, o tornou assunto de importante discussão por parte do pessoal da imprensa e das autoridades do setor de propaganda. Em 1923, o $12^{\circ}$ Congresso do Partido o mencionou pela primeira vez em suas resoluções. Com a primeira conferência dos colaboradores promovida pelo Departamento de Agitação e Propaganda e pelo Pravda em novembro de 1923, o movimento ganhou seu próprio veículo de discussão, 0 Correspondente Operário. 0 partido encampou o movimento e procurou dotar-lhe de meios para integrar 0 leitor à vida dos periódicos na condição de repórteres-correspondentes.

A expectativa dos jornalistas e oficiais de propaganda era a de que os correspondentes operários e camponeses exerceriam várias funções, entre as quais o monitoramento das autoridades 
locais, o registro do sentimento popular e a venda de assinaturas para os periódicos. Aguardando suas mensagens sobre os assuntos públicos e participação nos círculos de discussão locais, também esperavam que eles aprimorassem sua capacidade de escrever e raciocinar, a fim de participar responsavelmente do governo (Lenoe, 2004, p. 32).

Hicks observa bem que 0 movimento se desenvolveu prática e doutrinariamente repleto de ambiguidade e contradições, visto que, assim como os estudiosos mais atentos, também os seus sujeitos disputavam seu significado. Alguns divisavam nele uma forma de expressão da opinião popular e do supervisionamento público das instituições soviéticas no palco da vida cotidiana. Outros, porém, o entendiam como um mecanismo capilarizado e imediato através do qual os comunistas poderiam levantar informações e, cooptando ou alistando militantes, estender seu controle sobre a população soviética (cf. Hicks, 2006; Lenoe, 1999; Fitzpatrick, 1985, p. 165-166).

As tarefas e questões acadêmicas com que se envolveram os primeiros estudiosos soviéticos do jornalismo precisam ser vistas nesta situação, com a qual dialogaram para desenvolver uma abordagem relativamente original a respeito do assunto. A escolarização promovida pelo regime, mal ou bem, estava criando um público leitor cuja atenção era procurada pelo partido, e a forma de interpelar dividia suas várias tendências. 0 avanço da imprensa durante os primeiros anos da revolução bolchevique, por outro lado, não deve nos fazer ignorar que, apesar de tudo, era pequeno o poder de atração dos jornais e revistas publicados pelo regime.

A falta de papel nos primeiros tempos, os problemas de circulação, dadas as vastidões do território, as limitações técnicas existentes, o jargão doutrinário vigente e mesmo a visão pedagógica das tarefas da imprensa restringiam seu significado para as grandes massas, ainda em processo de alfabetizaçãa (cf. Brooks, 1985b). 0 pessoal que trabalhava no meio, recrutado entre os estamentos de origem burguesa, parecia incapaz de falar a língua do povo, sempre que se impunha muita obediência à cartilha partidária. 0 s casos de sucesso, em geral obtidos pelo jornalismo de boulevard independente, despertavam viva condenação pelos porta-vozes do jornalismo oficioso e pela política de propaganda do regime.

0 Instituto tendeu a se posicionar sobre toda esta situação defendendo a tese de que as tarefas de organização da opinião pública, propaganda ideológica e conscientização da cidadania soviética que os jornais devem assumir se processam "através da informação". A agitação é função secundária ou mesmo prejudicial, quando se trata de conduzir estes trabalhos. 0 ensino de jornalismo precisa prover o Estado e o partido de pessoas capacitadas em matérias especializadas, em vez de doutriná-las politicamente. A equipe era fiel ao regime, mas defendia que a informação era a essência do jornalismo. 0 jornalista precisa receber treinamento profissional sobre como trabalhá-la e, nisso, os princípios vigentes nos 
países burgueses poderiam servir de referência. A visão tecnicista assim esboçada, claro, não excluía a formação científica e humanista em distintas disciplinas, antes a exigia, embora houvesse tensão entre estas duas abordagens (cf. Mueller, 1998).

Adotando a sugestão de Lênin, segundo a qual a imprensa soviética não deveria se concentrar apenas em sua missão doutrinária, mas "investir na educação das massas", "verificando em detalhe" e "reunindo fatos" da "vida cotidiana" para "combater os defeitos e sugerir aprendizagem com os bons exemplos" (Lênin [1918] 1976, p. 157-160), seus principais porta-vozes advogavam que cabia àquela primeira difundir notícias e informação, combater a corrupção, vigiar os burocratas e, obedecendo aos princípios socialistas, servir de canal relativamente autônomo entre o povo e 0 governo.

Dentre os problemas de estudo a que se dedicou o Instituto, estavam o dos padrões de leitura e a linguagem dos periódicos, motivo de atenção por parte de vários órgãos da área de educação durante a década de 1920. Vinha do século XIX a preocupação com 0 assunto, de interesse não apenas para os reformadores daquela época, mas também para as casas editoriais e empresas jornalísticas (Zhirkov, 2011, p. 188-193). Em 1898, por exemplo, P. M. Shestakov estudou, mediante trabalho de campo e aplicação de entrevistas, os hábitos de leitura dos operários da indústria têxtil de Moscou.
Após a Revolução, foram feitas muitas enquetes com operários e camponeses, visando saber a situação socioeconômica de seus diversos setores, os quais também forneceram indicadores de consumo e dados de leitura a respeito de livros e periódicos. Os estudos sobre 0 assunto feitos no período anterior passaram por uma avaliação crítica e, depurados de suas premissas liberais, acabaram retomados por uma geração interessada em ajudar no avanço do comunismo.

Houve trabalhos de corte sociológico, às vezes conduzidos pelo partido, sobre os jornalistas e suas atividades (Juskevitz, 2002, p. 7-10). 0 principal em termos de pesquisa social empírica se encontra, no entanto, nos estudos sobre o perfil do leitor e seus padrões de leitura, estrategicamente mais importantes, considerando 0 interesse do regime em fazer contato e integrar as massas produtivamente ao estado soviético (cf. Dobrenko, 1997).

Lev Iakubinskii (1892-1946) explorou a dimensão sociolinguística do assunto em sucessivos estudos, enquadrando-a em uma fenomenologia da palavra pública na Rússia em obra de 1923. Para ele, apenas com o comunismo se abre a possibilidade de ela assumir um cunho massivo. Durante a Idade Média, a esfera pública era dominada pela Igreja, mas o jargão não permitia que esta última influísse de maneira profunda nas massas. A burguesia, mais tarde, introduziu o discurso político e parlamentar, mas também não logrou popularizá-lo, dadas as limitações de 
classe de sua publicidade. As massas, sobretudo no interior, seguiram presas ao discurso folclórico e, assim, a um pensamento conflitante com as ambições modernizantes não somente daquela classe, mas do novo regime soviético.

Engajado no trabalho de formação da militância, dos agitadores de que tanta mão lançavam as lideranças locais, Iakubinski desenvolveu várias técnicas em seu auxílio, obtendo resultados na luta contra esta situação (Smith, 1998, p. 67). Por outro lado, 0 autor sempre sustentou que a essência da linguagem se baseia no diálogo. A linguagem é uma síntese histórica e dialética entre o diálogo e o monólogo. 0 monólogo tem sua força, manifestando-se pela fala e escrita, mas inclusive quando falta interlocução presencial, o diálogo, como fala interna, está presente (cf. Dance, 1967).

Iakov Shafir (1887-1938) e Mikhail Gus (19031980) ampararam-se nessa linha de análise para pesquisar os problemas de leitura dos jornais e pensar formas de a imprensa soviética ajudar a solucioná-los. Autor de 0 jornal do trabalhador e seus leitores (1926), o primeiro conduziu vários estudos de campo sobre os hábitos e práticas de leitura dos camponeses e operários, chegando à conclusão que havia um hiato entre o público e a imprensa. 0 fato de esse público comprar e ler os jornais não significa que a mensagem daquela última estivesse sendo entendida e muito menos adotada na prática, conforme as autoridades esperavam, pela população. Os periódicos alinhados com 0 regime precisam abandonar a intuição, investir mais em pesquisa e se valer na prática de seus achados, se desejam conduzir seus trabalhos com mais chance de atingirem seus objetivos, argumentava Shafir (Brandist, 2015, p. 109-114).

Oriundo do meio, o autor foi crítico severo do jornalismo burguês, caracterizando como próprio de sua ideologia "a tendência a construir ilusões, encobrir ou obscurecer os vínculos sociais realmente existentes". Contudo, também fez duras ressalvas à propaganda de seu partido, ao constatar que, onde chegava, aquela tinha pouca influência na população. No interior, sobretudo, as pessoas em geral não a entendiam e, via de regra, se conduziam de acordo com rumores, em vez do que estava escrito nos jornais (Velikanova, 2013, p. 31-34).

Síntese de seus trabalhos, Questões de cultura jornalística (1927) concluiu que era preciso ir além do tratamento pontual. Para avançar, convinha desenvolver novas teorias, levando em conta as pesquisas e os estudos feitos no Ocidente. 0 campesinato não entendia a linguagem metropolitana empregada pela maior parte dos jornais, e somente com veículos radicalmente novos, feitos por coletivos especialmente treinados, seria possível alcançá-lo produtivamente desde 0 ponto de vista comunista (Brandist, 2015, p. 114).

Mikhail Gus, personagem muito notável da vida intelectual soviética durante várias décadas, 
endossou este diagnóstico em $A$ linguagem do jornal (1926). Amparado em ampla análise do assunto, ele, na verdade, foi além, ao teorizar a relação entre o jornal, o Estado e a sociedade. A linguagem do jornal precisa ser revolucionada, sim, mas isso não se faz sem a devida orientação teórica e intelectual. Coordenador da Comissão sobre a linguagem da imprensa, criada com o objetivo de promover orientação linguística mais consciente e produtiva entre os jornalistas soviéticos, 0 autor defendeu que a imprensa era e precisava ser entendida como um "fórum para as massas assimilarem e criticarem as questões práticas que afetam a vida do Estado" (Gus apud Smith, 1998, p. 40).

Em seu ver, o jornal serve de mediação entre o Estado e o povo, conforme provaria 0 movimento dos repórteres-correspondentes. 0 povo deve escutar e falar na dialética da imprensa: ele é seu objeto, mas também seu sujeito. "0 jornalista, sim, transforma o leitor", mas, por outro lado, "é transformado por este último", através de um "processo de constante interação, que transforma o jornal e é por sua vez transformado pelo jornal" (Gus apud Smith, 1998, p. 40). 0 marxismo vulgar fala da imprensa como reflexo mais ou menos fiel ou deformado da realidade, mas, de fato, "a única 'realidade objetiva', arguiu, é a encontrada no relacionamento dialético entre 0 jornal e seus leitores": 0 jornal "não é uma correia que, em mão-única, transmite a mensagem do partido para as massas" (Lenoe, 2004, p. 172).

\section{Do conceito de valor informativo à doutrina da opinião pública}

Durante os anos da nova política econômica, floresceram vários negócios na área cultural com fortes traços de escapismo, habilmente explorado por pequenos empreendedores da área de entretenimento. A imprensa de boulevard viveu breve renascimento, o qual repercutiu nas práticas e nas discussões sobre o modo como se fazia jornalismo. A exploração do sensacionalismo atraía leitores, lançando mão de recursos gráficos e técnicas de reportagem importadas da imprensa popular dos países capitalistas, superficialmente maquiados com um discurso pró-soviético.

Diante desta concorrência, a saída para os editores oficiais, muitas vezes, foi casar os padrões jornalísticos ocidentais, reconhecidamente marcados pela "ideologia burguesa", com "as explicações fornecidas pela doutrina comunista". "0s fatos eram importantes, mas precisavam de muita explicação, segundo os jornalistas demagógicos soviéticos" (Aratunyan, 2009, p. 96).

Instrutor no Instituto, Mikhail Levidov (18911942) procurou examinar e proceder à arbitragem desta situação em seu opúsculo $A$ imprensa informativa soviética (1924). Ex-assessor diplomático em Londres e publicista de ofício, 0 autor atacou a "cultura capitalista de massas". Para ele, o cinema, o rádio e os tabloides se tornaram formas de ajudar os trabalhadores a se 
recuperar da fadiga gerada durante 0 expediente. As mentiras contadas à classe trabalhadora entraram em um novo estágio de alienação com 0 advento dos jornais populares. Os jornais burgueses haviam passado a se caracterizar pelo esforço em distrair seus leitores. 0 problema, porém, não era mais exclusivo dos países capitalistas.

Para 0 autor de 0 Homem e o cinema: um estudo de estética sociológica (1927), a União Soviética também estava se tornando palco dele. 0 jornalismo primitivo e vulgar dos países capitalistas igualmente emergira no seu. Seria 0 caso de censurá-lo? Levidov não acreditava nisso como melhor opção. Afinal, a imprensa soviética também não estava livre de problemas. A saída indicada seria aprender com o jornalismo ocidental. 0 fato de o jornalismo sensacionalista estar avançando era sinal de que chegara a hora para 0 soviético repensar sua situação de acordo com novas premissas psicológicas e sociais. 0 fato de a imprensa burguesa estar cada vez mais degenerada não significa que não havia nela 0 que aprender e, eventualmente, desenvolver, ou seja: a arte de recolher, selecionar e editar informações, ainda não dominada por seus conterrâneos (Korkonosenko, 2001, p. 91-93).

\section{0 jornalismo soviético precisa superar a} passividade e o mecanicismo que vigoram em seu serviço noticioso. As seções devem ser melhor cuidadas, tanto do ponto de vista da edição quanto da apresentação. Ao pessoal, convém reforçar os contatos e ampliar os laços com os leitores, não apenas porque eles podem ser úteis para revisar seus erros. A participação do leitor é um fator motivacional muito importante para o próprio consumo e penetração dos jornais em seu segmento de público. 0 jornalismo soviético esconde um temor por trás de sua condenação do jornalismo de boulevard, o que não se admite. Os tabloides não devem ser temidos, mas apreendidos prática e teoricamente em sua dialética. A paginação mais atraente e a exploração da fotografia a que eles procedem sinalizam um interesse estético que não deveria mais ser desprezado pelas publicações mais comprometidas com o regime (Lenoe, 1998, p. 43-44).

0s problemas humanos e histórias de vida que os empresários pequeno-burgueses tão vulgarmente exploram podem e precisam ser resgatados dialeticamente pela imprensa bolchevista. Os seus redatores se preocupam demais com o que ocorre no mundo político e econômico, para não falar no exterior, sem notar que 0 cidadão comum concentra seu foco no que é próximo e imediato. A maneira de, eventualmente, levá-lo a se interessar por assuntos de mais amplo espectro só pode ser alcançada explorando com inteligência o noticiário local e os fait-divers (cf. Korkonosensko, 2001, p. 91-93).

Aleksandr Kurs (1892-1937), também crítico de jornal, roteirista de cinema (A jornalista, 1927) e professor, seguiu por esta linha ao defender uma formação essencialmente jornalística para os estudantes do Instituto. Em seu ver, o único jeito de formar pessoas melhor preparadas para 
a imprensa soviética era salientando o cunho

fundacional do conceito de informação no exercício do jornalismo. Como Novitski, Levidov e outros, ele acreditava que o jornalismo soviético tinha muito que aprender da imprensa burguesa dos países avançados.

Kurs salientou a importância da "informação" como fundamento de todos os tipos de jornalismo, seja burguês, seja comunista, recomendando 0 estudo da "teoria burguesa da informação". Ele argumentou que a informação era um ingrediente essencial da imprensa russa, porque os jornais soviéticos "organizam, agitam, propagandeiam, educam e reposicionam a personalidade com base na informação" (Mueller, 1998, p. 72).

Para ele, o conceito central com que a atividade trabalha não é a opinião, mas o de informação.

A informação é 0 valor com que trabalha 0 jornalismo. As publicações propriamente jornalísticas, sendo bem feitas, dispensam elaborações adicionais, como pretendiam outros pesquisadores. A composição da notícia, por si só, valoriza a informação, um conceito de ordem qualitativa, que fora notado por Trostki (Rüdiger, 2016) e, em seguida, apropriado e desenvolvido por seu colega Mikhail Gus.

Kurs explicou que o conceito de valor informativo tinha a ver com a diferença entre um fenômeno e outro que justifica sua transformação em notícia, identificando-a pelas características da unicidade, novidade e originalidade. 0 valor informativo é o fator de atração do público para a notícia. Gus empregou a expressão valor noticioso, acrescentando às características citadas a dimensão do propósito. 0 autor definiu 0 artigo informativo como 0 meio ou forma de comunicação comandada pelo interesse em promover a compreensão imediata (Smith, 1998, p. 66).

Conforme ele argumentou em $A$ informação no jornal (1930), o valor da informação, todavia, também é determinado pelo impacto, a diferença que uma matéria provoca ou não no contexto de uma campanha informativa ou propagandística. 0 fato de os jornais soviéticos serem muito dependentes dos protocolos linguísticos e doutrinários estipulados pelo partido os enfraquece.

Gus defendeu que a melhor forma de fazer propaganda para as massas era através de cuidadosa seleção de fatos cotidianos, criticando os jornais de seu país por sua incapacidade em "lidar com os fatos, em usá-los de forma mais apropriada e exaustiva" (Lenoe, 2004, p. 156).

Os clichês e slogans que enchem suas páginas empobrecem a expressão ideológica, gerando desinteresse entre os leitores. Os repórteres ficam amarrados a fórmulas, em prejuízo da informação que caberia dar ao leitor. 0 público se mantém desinformado, a ponto de até os estímulos emocionais que as matérias podem conter não surtirem efeito. A reportagem cheia de vida, feita sem medo de cair no sensacionalismo, é um jeito comparativamente melhor de combater a burocracia no jornalismo e agitar 0 sentimento revolucionário das massas (Smith, 1998, p. 66-67). 
Vladimir Kuzmichev (1903-1994), formado jornalista no Instituto e assistente de pesquisa até 1932, procurou compor todas estas teses e ideias com uma versão mais bitolada do marxismo, a teoria da informação de classe com a doutrina leninista da propaganda, em $A$ organização da opinião pública (1929). Para ele, a opinião pública é função do sistema socioeconômico, e não dos costumes/tradição, como querem os conservadores, nem da livre concorrência de opiniões individuais, como desejam os liberais. A opinião pública surge através da intervenção de instituições, é um estado de consciência que emerge do trabalho de organização, depreendeu de sua leitura de Lênin, corroborado, segundo ele, pelo burguês Lippmann ([1922] 2008).

No caso dos países capitalistas, a opinião pública é fruto da ação das forças do mercado e, assim, possui um caráter anárquico. A regra é ela ser trabalhada de maneira mais ou menos enganosa ou fraudulenta pelos jornais, como observara Lênin ([1917] 1976, p. 150-156). No caso do estado comunista, ao contrário, a opinião pública pode e deve surgir organicamente, através da ação do partido e seus meios de influência/propaganda.

Destarte, para 0 autor também, a consciência adquire força social objetiva, capaz de influir no rumo dos acontecimentos, ao passar por instituições ideológicas como a imprensa (Voloshinov, [1929] 1981, p. 120) - mas isso não é mecânico, nem automático. A opinião pública não é uma entidade bruta: tem sempre e a cada vez de ser examinada e trabalhada como processo. 0 fato de ela surgir da interação dialética das opiniões individuais fomenta as tendências anárquicas da economia no capitalismo e dificulta o combate ao individualismo no estado comunista. Acontece, no entanto, que, neste último caso, existe no comando um partido representativo dos interesses da maior parte da sociedade para mediar 0 processo e providenciar a superação de suas contradições (Volkov, 1998, p. 62).

Tirando as consequências dos estudos de Shavir e Gus, Kuzmichev descobriu, em suas pesquisas, que 0 governo soviético ainda não conseguira formar uma opinião pública sintonizada com seu projeto de transformação da sociedade. As pessoas ainda se comportavam de maneira irracional, seguindo rumores, devido à influência negativa exercida pelo próprio partido. Ao partido caberia, portanto, reformar seus métodos de propaganda, para poder influir positivamente na formação e condução opinião pública soviética.

Nesse sentido, as pesquisas de opinião e as análises de conteúdo de origem burguesa poderiam servir de ajuda, na medida em que fornecessem informações para as autoridades planejarem sua ação propagandística. 0 problema dos rumores, que ele jamais pensou como tendo origem na própria ação política do partido (Velikanova, 2013), além de estar sujeito à punição penal, pode e deve ser combatido sistematicamente com a ajuda da imprensa, argumentou Kuzmichev (Volkov, 1998). 
A expressão da atitude opiniática do público, como este mesmo, é sempre função, em uma sociedade de massas, da ação organizativa. A falta desta ação pode importar no surgimento de rumores e, assim, em situações nocivas, se não potencialmente perigosas para 0 Estado. Os trabalhos de organização precisam de constância, porque as interações que lhe dão origem se modificam diariamente, embora elas não necessariamente impliquem em mudança de qualidade no imediato. A possibilidade de controle via imprensa depende da pesquisa sobre a percepção do público acerca dos assuntos de interesse do Estado.

Os jornais podem ajudar a combater a emergência de opiniões imaturas e a desorganização da vida pública inerentes à grande sociedade, levando as massas a passar do interesse egoísta ao coletivo. A pesquisa a respeito do problema e 0 desenvolvimento de novas formas de explorar 0 veículo têm nisso um papel estratégico a desempenhar, estavam mais ou menos de acordo os integrantes do Instituto.

\section{Epílogo}

No final de 1930, o estabelecimento, entretanto, foi fechado para dar lugar a um novo, o Instituto Comunista de Jornalismo, cujas filiais se estenderiam, com 0 tempo, a diversas outras cidades do país, sempre de modo separado das Universidades. Houve uma violenta polêmica entre os defensores da doutrina da informação de classe, associados pelos opositores à facção trotskista, e os partidários da doutrina leninista da imprensa como forma de organização, encampada pelos seguidores de Stalin (cf. Lenoe, 2004, p. 171-173).

A congregação existente foi em sua maioria dispensada e, em seu lugar, assumiu um corpo de instrutores diretamente subordinado ao Comitê Central do Partido Comunista. A atividade de pesquisa e a reflexão teórica praticamente desapareceram. A primeira preocupação passou a ser formar recursos humanos para trabalhar nos órgãos de imprensa e no Estado. 0 ensino se tornou essencialmente técnico, com alguma complementação doutrinária baseada em textos de Lênin e Stalin.

Após a II Guerra, os oficiais de propaganda e diretores de jornais a eles acrescentaram os chamados princípios leninistas da imprensa, um conjunto bastante aberto e flutuante de diretrizes, derivado de suas doutrinas sobre 0 assunto e que compreendia o compromisso com o partidarismo, a prática regular da autocrítica, a fidelidade ideológica, a orientação classista, a massividade, 0 internacionalismo, a agilidade e outras noções similares (cf. Hollander, 1967, p. 26-36).

Acusado de desviacionismo e condenado a um exílio interior, Mikhail Gus logrou escapar dos expurgos ocorridos nos anos 1930 e 40. Como Kuzmichev, reintegrou-se às atividades editoriais e acabou tendo certo protagonismo 
na história intelectual soviética. Shafir, suspeito de trotskismo, saiu de cena sem deixar marcas, desaparecendo em 1938. Kurs foi, primeiro, banido do partido, mais tarde assassinado na prisão, durante uma das ondas de perseguição dos anos 1930. Levidov sumiu durante outra, em 1937, sendo dado como morto no cativeiro em 1942.

\section{Referências}

ARATUNYAN, Ana. The media in Russia. Nova York: McGraw-Hill, 2009.

BENN, David. Persuasion and soviet politics. Oxford: Blackwell, 1989.

BRANDIST, Craig. The dimensions of hegemony. Leiden: Brill, 2015.

BRINE, Jennifer. Adult readers in the Soviet Union. Birmingham: Birmingham University, 1985.

BR00KS, Jeffrey. Information and power. Chicago: National Council for Soviet and East European Research, 1985a.

. The breakdown in production and distribution of printed material, 1917-1927. In GLEASON, A. et al. Bolshevik culture. Bloomington: Indiana University Press, 1985b.

BRUNELLO, Piero (org.) Anton Tchekhov: Bom par de sapatos e um caderno de anotações - como fazer uma reportagem. São Paulo: Martins Fontes, 2008.

BÜCHER, Karl. Gesammelte Aufsätze zur

Zeitungskunde. Tübingen: Laupp, 1926.

BYFORD, Andy. Literary scholarship in late Imperial Russia. Londres: Legenda, 2007.

CLIBBON, Jennifer. The soviet press and grassroots organization. Ann Arbor: Toronto University Press. 1993.
DANCE, Frank. Speech communication research in the Soviet Union. In THAYER, Lee (org.). Communication theory and research. Springfield: Thomas, 1967.

DAVID-FOX, Michael. Revolution of the mind. Ithaca: Cornell University Press, 1997.

DAVIES, Sarah. Public opinion in Stalin Russia. Cambridge: Cambridge University Press, 1987.

DOBRENKO, Evgeny. The making of the state reader. Stanford: Stanford University Press, 1997.

DUNAS, Denis. Mapping communication theories in contemporary Russia. In VARTANOVA, Elena. World of Media. Moscou: Faculdade de Jornalismo/Universidade de Moscou, 2013.

FITZPATRICK, Sheila. The cultural front. Ithaca: Cornell University Press, 1992. Everyday stalinism. In GLEASON,

A. et al. Bolshevik culture. Bloomington: Indiana University Press, 1985. Cultural Revolution as class war. In FITZPATRICK, Sheila (orga.). Cultural Revolution in Russia 1928-1931. Blomington: Indiana University Press, 1978.

GUICHARD, Benjamin. Les usages révolutionnaires de la liberté de la presse. In Siècles v. 27, p. 49-61, 2008.

HAMBURG, G. M. Russian intelligentsia. In LEATHERBARROW, W.; OFFORD, D. (orgs.). A history of russian thought. Cambridge: Cambridge University Press, 2010.

HARRISON, Marguerite. Marooned in Moscow. Nova York: Doran, 1921.

HICKS, Jeremy. From conduits to commanders. In Revolutionary Russia, v. 19, n. 2, p. 131-149, 2009.

HOLLANDER, Gayle. Soviet newspapers and magazines. Cambridge: Center for international studies (IMT), 1967. 
JAEGER, Karl. Von der zeitungskunde zur publizistichen wissenschaft. Berlim: Volker Spiess [1926) 1996.

JUSKEVITS, Svetlana. Professional roles of Russian journalists at the end of the 1990s. Tampere: University of Tampere, 2002.

KASHKIN, Viacheslav. Russian communication studies. Russian Journal of communication v. 6 , n.1, p. 89-92, 2014.

KENEZ, Peter. The birth of state propaganda. Cambridge: Cambridge University Press, 1985.

KORKONOSENKO, Sergei. Russian journalism theory in a changing global context. In Asian Social Science, v. 11, n. 1, p. 329-334, 2015. . Voices from the field. In Russian Journal of Communication v. 6, n. 2, p. 155-159, 2014. Osnovi zhurnalistiki. Moscou: Aspect, 2001.

KRUNGLAK, Theodore. The two faces of Tass.

Minneapolis: Minnesota University Press, 1962.

KRUPSKAYA, Nadezhda. La educación comunista.

Madri: Nueva Cultura, 1978.

LENIN, V. Prensa y literatura. Madri: Akal, 1976.

LENOE, Matthew. Closer to the masses. Cambridge: Harvard University Press, 2004.

\section{Agitation, Propaganda, and}

the 'Stalinization' of the Soviet Press, 1922-1930.

Pittsburgh: The Center for Russian and East European Studies, 1998

LIPPMANN, Walter. Opinião pública. Petrópolis: Vozes, [1922] 2008.

LITVINENKO, Anna. A new definition of journalism functions in the framework of hybrid media systems. In Global Media Journal, Foster City, v. 3, n. 1, p. 1-12, 2013.
LOWELL, Stephen. The Russian reading revolution. Londres: Palgrave, 2000.

Russia in microphone age.

Oxford: Oxford University Press, 2013.

MARTINSEN, Deborah (orga.). Literary journals in Imperial Russia. Cambridge: Cambridge University Press, 1997.

McREYNOLDS, Louise. The news under Russia's old regime. Princeton: Princeton University Press, 1991. . Autocratic journalism. In Slavic Review v. 49, n. 1, p. 48-57, 1990.

MEDEIROS, Gutemberg. Dostoievski, jornalista. Covilhã: Universidade da Beira Interior, 2007.

MEDVEDKIN, Alexander. El cina como propaganda politica. Buenos Aires: Siglo XXI, 1973.

MORRISON, J. The changing model of Russian media and journalism education. In Journalism \& Mass Communication Education, v. 52, n. 3, p. 26-34, 1997. MUELLER, Julie. Soviet journalists. In Russian History v. 23, n. 1, p. 277-284, 1996. . Staffing newspapers and training journalists in early Soviet Russia. In Journal of Social History, v. 31, n. 4, p. 851-873, 1998.

PASTI, Svetlana. Two generations of contemporary russian journalists. In European Journal of Communication, Londres, v. 20, n. 1, p. 89-115, 2005. PROKHOROV, E. P. Press journalism. In Great Soviet Encyclopedia. 3a. ed. Farmington Hills: Gale Group, 1973-1979a. Disponível em www.thefreedictionary.com Acessado em 17/11/2015.

Publicistics. In Great Soviet

Encyclopedia. 3a. ed. Farmington Hills: Gale Group, 1973-1979b. Disponível em www.thefreedictionary.com Acessado em 17/11/2015. 
REMINGTON, Thomas. The truth of authority. Pittsburgh: University of Pittsburgh Press, 1988.

RÜDIGER, Francisco. 0 pensamento jornalístico comunista nos anos 1920: Fogarasi, Trotski e Gramsci (a sair, 2016).

RUUD, Charles. Russian entrepeneur. Montreal: McGill-Queen's University Press, 1990.

SMITH, Michael. Language and power in the creation of USSR. Berlin: Mouton de Gruyter, 1998.

STALIN, J. The press as a collective organiser. In Works, Vol. 5, 1921 - 1923. Foreign Languages Publishing House, Moscow, [1923a] 1954.

TOLSTIKOVA-MAST, Y., KEYTON, J. Communicating about communication. In Bulletin of Russian Communication Association v. 1, p. 119-134, 2002.

TROTSKI, Leon. Problems of everyday life. Nova York: Monad, [1927] 1973.

TUCKER, Robert. Lenin's bolshevism as culture in the making. In GLEASON, A. et al. Bolshevik culture. Bloomington: Indiana University Press, 1985.

VARTANOVA, Elena. De-sovietizing Russia media studies. In THUSSU, Daya (org.). Internationalizing media studies. Londres: Routledge, 2009.

VELIKANOVA, Olga. Public opinion perceptions of soviet politics in the 1920's. Londres: Palgrave, 2013.

VOLKOV, Vadim. Obshchestvennost: an indigenous concept of civil society? In HEKINNEN, K.;

ZDRAVOMYSLOVA, P. (orgas.). Civil society in the

European North. São Petersburgo: Centro de Pesquisa Social Independente, 1998.

. The limits of propaganda. RAVEN,

J. (org.) Free Print and Non-Commercial Publishing. Londres: Ashgate, 2000.

VOLOSHINOV, Valentin. Marxismo e filosofia da linguagem. São Paulo: Hucitec, [1929] 1981.
VOROSHILOV, V. Journalism, a textbook. 2 ed. São Petersburgo: Mihajlova, 2000.

ZENKI, Asaoka. Nikolai Bukharin and the Rabsel'kor movement. In YASHUIRO, M. (Org.) Obshchestvennost' and Civic Agency in Late Imperial and Soviet

Russia. Londres: Palgrave, 2015.

ZHIRKOV, Gennady. Journalism and journalism theory in Russia. In Russian Journal of Communication v. 4, n. 3-4, p. 177-197, 2011.

WOLF, Erika. The context of early soviet photojournalism. In Zimmerli Journal, v. 2, p. 106-117, 2004. 


\section{The Moscow University Institute and the soviet journalism studies of the 1920's: an unfinished scientific project}

\section{Abstract}

We still have few information in the West about a scientific research program and a theoretical system for reflection and analysis of the press in a communist society that arose at the Institute of Journalism created by soviet authorities inside the Moscow State University during the 1920s. This article presents the circumstances, the protagonists, the main ideas and the core lines of study that defined this phenomenon, occurred during the period the country experienced the "new economic policy". We argue that in those years Soviet scholars endeavored to develop a Marxist theory of class information in order to maintain a relative autonomy of journalism in front of the Leninist doctrine of propaganda and organization officially professed by the regime.

\section{Keywords}

Theories of journalism. Marxism. Soviet school.

\section{El Instituto de la Universidad de Moscú y los estudios de periodismo soviéticos de los años 1920: un proyecto cientifico sin terminar}

\section{Resumen}

Aún tenemos poca información en Occidente acerca de un programa de investigación científica y un sistema teórico de reflexión y análisis de la prensa en una sociedad comunista que surgió en el Instituto de Periodismo creado e mantenido por las autoridades soviéticas dentro de la Universidad Estatal de Moscú durante la década de 1920. Este artículo presenta las circunstancias, los protagonistas, las ideas centrales y las líneas principales de estudio que han definido este fenómeno, ocurrido durante los años en que el país experimentó la "nueva política económica". Se argumenta que durante el período de los científicos soviéticos han hecho un esfuerzo por desarrollar una teoría marxista de la información de clase con el fin de mantener una autonomía relativa del periodismo frente a la doctrina leninista de la propaganda y la organización profesada oficialmente por el régimen.

\section{Palabras clave}

Teorias del periodismo. Marxismo. Escuela soviética. 


\section{Expediente}

A revista E-Compós é a publicação científica em formato eletrônico da Associação Nacional dos Programas de Pós-Graduação em Comunicação (Compós). Lançada em 2004, tem como principal finalidade difundir a produção acadêmica de pesquisadores da área de Comunicação, inseridos em instituições do Brasil e do exterior.

\section{E-COMPÓS I www.e-compos.org.br I E-ISSN 1808-2599}

Revista da Associação Nacional dos Programas de Pós-Graduação em Comunicação.

Brasília, v.19, n.1, jan./abr. 2016.

A identificação das edições, a partir de 2008, passa a ser volume anual com três números.

Indexada por Latindex I www.latindex.unam.mx

\section{CONSELHO EDITORIAL}

Alexandre Farbiarz, Universidade Federal Fluminense, Brasil Alexandre Rocha da Silva, Universidade Federal do Rio Grande do Sul, Brasil Ana Carolina Damboriarena Escosteguy, Pontifícia Universidade Católica do Rio Grande do Sul, Brasil

Ana Carolina Rocha Pessôa Temer, Universidade Federal de Goiás, Brasil Ana Regina Barros Rego Leal, Universidade Federal do Piaú, Brasil Andrea França, Pontifícia Universidade Católica do Rio de Janeiro, Brasil André Luiz Martins Lemos, Universidade Federal da Bahia, Brasil Antonio Carlos Hohlfeldt, Pontifícia Universidade Católica do Rio Grande do Sul, Brasil

Arthur Ituassu, Pontifícia Universidade Católica do Rio de Janeiro, Brasil Álvaro Larangeira, Universidade Tuiuti do Paraná, Brasil

Ângela Freire Prysthon, Universidade Federal de Pernambuco, Brasil César Geraldo Guimarães, Universidade Federal de Minas Gerais, Brasil Cláudio Novaes Pinto Coelho, Faculdade Cásper Líbero, Brasil Daisi Irmgard Vogel, Universidade Federal de Santa Catarina, Brasil Denize Correa Araujo, Universidade Tuiuti do Paraná, Brasil Eduardo Antonio de Jesus, Pontifícia Universidade Católica de Minas Gerais, Brasil

Daniela Zanetti, Universidade Federal do Espirito Santo, Brasil Eduardo Vicente, Universidade de São Paulo, Brasil Elizabeth Moraes Gonçalves, Universidade Metodista de São Paulo, Brasil Erick Felinto de Oliveira, Universidade do Estado do Rio de Janeiro, Brasil Francisco Elinaldo Teixeira, Universidade Estadual de Campinas, Brasil Francisco Paulo Jamil Almeida Marques, Universidade Federal do Paraná, Brasil

Gabriela Reinaldo, Universidade Federal do Ceará, Brasil Goiamérico Felício Carneiro Santos, Universidade Federal de Goiás, Brasil Gustavo Daudt Fischer, Universidade do Vale do Rio dos Sinos, Brasil Herom Vargas, Universidade Municipal de São Caetano do Sul, Brasil Itania Maria Mota Gomes, Universidade Federal da Bahia, Brasil
Janice Caiafa, Universidade Federal do Rio de Janeiro, Brasil Jiani Adriana Bonin, Universidade do Vale do Rio dos Sinos, Brasil José Afonso da Silva Junior, Universidade Federal de Pernambuco, Brasil José Luiz Aidar Prado, Pontifícia Universidade Católica de São Paulo, Brasil Juçara Gorski Brittes, Universidade Federal de Ouro Preto, Brasil Kati Caetano, Universidade Tuiuti do Paraná, Brasil Lilian Cristina Monteiro França, Universidade Federal de Sergipe, Brasil Liziane Soares Guazina, Universidade de Brasilia, Brasil Luíza Mônica Assis da Silva, Universidade de Caxias do Sul, Brasil Luciana Miranda Costa, Universidade Federal do Pará, Brasil Malena Segura Contrera, Universidade Paulista, Brasil Maria Ogécia Drigo, Universidade de Sorocaba, Brasil Maria Ataide Malcher, Universidade Federal do Pará, Brasil Marcia Tondato, Escola Superior de Propaganda e Marketing, Brasil Marcel Vieira Barreto Silva, Universidade Federal da Paraíba, Brasil Maria Clotilde Perez Rodrigues, Universidade de São Paulo, Brasil Maria das Graças Pinto Coelho, Universidade Federal do Rio Grande do Norte, Brasil

Mauricio Ribeiro da Silva, Universidade Paulista, Brasil

Mauro de Souza Ventura, Universidade Estadual Paulista, Brasil Márcio Souza Gonçalves, Universidade do Estado do Rio de Janeiro, Brasil Micael Maiolino Herschmann, Universidade Federal do Rio de Janeiro, Brasil Mirna Feitoza Pereira, Universidade Federal do Amazonas, Brasil Nísia Martins Rosario, Universidade Federal do Rio Grande do Sul, Brasil Potiguara Mendes Silveira Jr, Universidade Federal de Juiz de Fora, Brasil Regiane Regina Ribeiro, Universidade Federal do Paraná, Brasil Rogério Ferraraz, Universidade Anhembi Morumbi, Brasil Rose Melo Rocha, Escola Superior de Propaganda e Marketing, Brasil Rozinaldo Antonio Miani, Universidade Estadual de Londrina, Brasil Sérgio Luiz Gadini, Universidade Estadual de Ponta Grossa, Brasil Simone Maria Andrade Pereira de Sá, Universidade Federal Fluminense, Brasil Veneza Mayora Ronsini, Universidade Federal de Santa Maria, Brasil Walmir Albuquerque Barbosa, Universidade Federal do Amazonas, Brasil

\section{COMISSÃO EDITORIAL}

Cristiane Freitas Gutfreind, Pontifícia Universidade Católica do Rio Grande do Sul, Brasil Irene Machado, Universidade de São Paulo, Brasil

Eduardo Antonio de Jesus, Universidade Católica de Minas Gerais, Brasil

\section{CONSULTORES AD HOC}

Cleusa M. Andrade Scroferneker, Pontifícia Universidade Católica do Rio Grande do Sul, Brasil Francisco Rüdiger, Pontifícia Universidade Católica do Rio Grande do Sul, Brasil Juliana Freire Gutmann, Universidade Federal da Bahia, Brasil Karla Regina M. P. Patriota Bronsztein, Universidade Federal de Pernambuco, Brasil Laura Loguercio Cánepa, Universidade Anhembi Morumbi, Brasil Lucia Isaltina C. Leão, Pontifícia Universidade Católica de São Paulo, Brasil

\section{EQUIPE TÉCNICA}

\section{ASSISTENTE EDITORIAL I Márcio Zanetti Negrini}

REVISÃO DE TEXTOS I Press Revisão

EDITORAÇÃO ELETRÔNICA I Roka Estúdio

CONTATO I revistaecompos@gmail.com
COMPÓS I www.compos.org.br

Associação Nacional dos Programas de Pós-Graduação em Comunicação

Presidente

Edson Fernando Dalmonte

Programa de Pós-Graduação em Comunicação

e Cultura Contemporânea - UFBA

edsondalmonte@uol.com.br

Vice-presidente

Cristiane Freitas Gutfreind

Programa de Pós-Graduação em Comunicação Social - PUC-RS cristianefreitas@pucrs.br

Secretário-Geral

Rogério Ferraraz

Programa de Pós-Graduação em Comunicação

Universidade Anhembi Morumbi

rogerioferraraz@anhembimorumbi.edu.br 